\title{
Role of Lecturers Engangement To Improving Aceh Private University Performance During Covid-19
}

\author{
Muhammad Zainal Abidin ${ }^{1, *}$ Abdul Rahman Lubis ${ }^{2}$, Nurdasila Darsono ${ }^{3}$, Muslim A \\ Djalil $^{4}$ \\ 1,2,3,4 Economic and Business Faculty, Universitas Syiah Kuala \\ *Corresponding author. Email: zenal1978@gmail.com and rahmanlubis54@yahoo.com
}

\begin{abstract}
We investigated the relationship between employee engagement, meeting applications, leadership and organization performance. This research combines the social media usage model that has been developed previously with the engagement model by William Khan. This research uses quantitative methods with a population of private universities in Aceh Province and takes a sample of 280 lecturers using purposive sampling technique based on certain criteria. The results of the structural equation model analysis show that the performance of private universities in Aceh during pandemic covid-19 can be influenced by employee engagement, application meetings, and leadership.
\end{abstract}

Keywords: employee engagement, meeting application, leadership, organization performance

\section{INTRODUCTION}

One of the causes is employee engagement, beginning from the motivation to enhance performance, [1] which leads to a simple theory that can explain the cause and effect of employee engagement (EE), namely the theory of social exchange. Essentially, this theory claims that responsibilities are resulting from a sequence of encounters between the two interdependent parties. Social exchange theory assumes that, as long as both parties follow the rules of exchange, there is a relationship which develops from time to time into a trusting, loyal and committed connection.[2] Besides, this principle tends to evolve in such a way that a motivation theory emerges that also influences success improvement, [3][4][6] success is also the product or accomplishment of both the efforts of individuals and organizations. In addition to commitment, some other variables and triggers can contribute to increased or decreased efficiency. The position of factors such as leadership (LD) that can contribute to improving organizational efficiency. [7][8][9] In addition to these several factors, efficiency may also be enhanced by the role of other factors, such as employee engagement, which is usually employee engagement or linked to employee engagement within a business or organization, as well as technology that is part of external factors. [10] [11] [12] [13]
Research related to organizational performance continues to expand. Employee engagement, also known as employee engagement, in affecting the efficiency of a service organization is an interesting topic to create. This body is a private higher education institution in the province of Aceh, which includes a significant number of human or human resources staff in its organizational activities. Organizational performance will be strengthened by the participation of current human capital in the organisation, as well as by the support and technology investment that continues to develop. To promote improved organizational performance, the Internet and its supporting software must be streamlined. [14] Besides, the role of various organizations in the field of Android applications and information technology is often very likely to be developed and implemented to attract and sustain the presence of an organization among competitors. [15]

Various analyses of LD, EE and organizational performance (OP) have been developed in previous research. [13][12][16] Besides, organizational performance can also be affected by technological developments in the form of different applications, such as social media, which may have a negative or positive effect on organizational performance, either directly or indirectly. [17] [15]

This research would thus begin by examining the impact of the variables EE (lecturer engagement) and $\mathrm{OP}$ (university performance) on the LD (leadership) 
variable and as an antecedent of EE and OP. To fill the research gap on the limitations of previous research, this study will introduce a meeting application variable (System Knowledge Management-MASIM) on the effect of the EE and OP variables as a moderating variable.

Limitations on the evaluation of organizational performance through the position of LD, EE and the moderating variable MASIM are key issues in this report. Improving organizational efficiency through the $\mathrm{EE}$ as an antecedent and adding the MASIM variable is expected to have a positive impact and improve the effect of EE on OP since prior research did not relate empirically between the roles of LD, EE, MASIM and $\mathrm{OP}$ in private higher education institutions. This research also incorporates and analyzes models and tests some of these variables that may influence organizational performance either directly or indirectly through the MASIM variable.

\section{LITERATURE REVIEW}

Before this, there were several reports on business success linked to employee engagement. Some researchers suggest that there is a significant relationship between the role of employee engagement in organizational success. [18][19][20][21][22] Furthermore, it continues to develop engagement theory and performance-related theory. Previous researchers have noted that there is a relationship between the use of IT technology (in this study the MASIM variable) and the profitability of the organisation. Research on the analysis of the role of Environment and Information Technology (ET \& IT) in Lean Manufacturing (LM) in achieving increased industrial performance, [23] shows different results from previous literature, it has been found that there has been an increase in consumer needs concerning response times and environmental issues, it is recommended for increased work to be carried out, stores must. The hypothesis was tested in the context of a multisectoral sample of 763 factories (NACE code 1537) from five separate European countries. The results of the analysis show that the overall mediation of technology is between weak routine ties and industrial efficiency, requiring LM (lean production) to create efficient conditions for the development of technical adaptability that can be used to boost industrial performance. From a managerial perspective, the need to avoid short-sightedness and internalization of technology generation in transformation projects has been identified as lean. This is important not only because technology is crucial to maximizing the potential of organizational routines in today's manufacturing systems, but also because of its inherent benefits. Further research has shown that, from the perspective of the Competence Activity Model (ACM) and previous research, researchers have developed a conceptual structure to examine the capacities of IT management staff and their effect on performance. [24] On the other hand, [24] Quantitative analysis approaches have been developed in the form of a measurement scale used to assess the efficacy and managerial capability of the CIO. The least-square approach is partly used to test the conceptual model empirically and the conclusions are verified by data obtained in large-scale surveys. The results positively support the proposed structure model in the analysis, and the findings of the test hypotheses indicate that both IT and managerial competence have a substantial positive impact on the efficacy of the CIO. Researchers have found that IT management capabilities have a major impact on CIO efficiency. The results of this study have added value and may serve as a reference point for potential researchers focusing on IT management training and the development of skills for CIOs. Besides, it was shown in other studies that technically there is a distinction between job attachment from the idea of burnout from a task level perspective. [25] In particular, the authors claim that work attachments (i.e. familiarity with the application of vigor, commitment and absorption factors) occur during the work process. [26] They were, of course, different for each person, and not only fluctuate from one day to the next (or even regularly), but they can vary greatly from one job to another. Burnout (and particularly associated with the fatigue factor) as a chronic illness does not vary from one job to another. The authors define task features derived from job characteristics models as predictors of task-specific employee engagement and explain how the relationship between developed technological, on the one hand, and worklevel social and personal resources, on the other. [27] Researchers also outline potential alternate directions for future study and explore practical consequences, including task design and employee energy management during the working day. Later in this journal, it is also mentioned that this viewpoint on job-specific work participation illustrates the distinction between work involvement and burnout in a different way than in previous studies. Previous studies have shown that there is an empiric association between attachment and fatigue and have tested the discrepancy between the construct and the factor-analytical method. [28][29] Further research indicates that the safety climate is a measure of the degree to which safety can be felt by employees as a priority in their business, and this problem is also a key factor in encouraging conduct that reduces the risk of accidents and injuries and a healthy working atmosphere. [30] Using the theory of social exchange as a theoretical basis, this study hypothesizes that the safety environment would be connected to employee satisfaction, engagement and attrition rates, which further highlights the beneficial effects of the safety climate. Data from the survey were obtained from 6207 truck drivers from two truck companies in the United States. The objective turnover rate was collected one year after the survey data were collected. Results have shown that perceptions of the safe environment of workers, when combined with the degree of work satisfaction, commitment and turnover goals, promote 
the implementation of the social exchange principle. Job satisfaction is also a major mediator between the atmosphere of safety and human resource results (i.e. employee retention and turnover). The research is one of the first to examine climate impacts on safety beyond the safety outcomes of self-employed employees (using truck drivers as an example). Further findings suggest that understanding of the co-developmental dynamics between fatigue and work attachment is limited due to lack of long-term follow-up and fluctuating data studies. [31] The purpose of this study is to identify a sub-group of employees characterized by long-term exhaustion (energy continuum) and cynicism (continuum identification). Another significant goal is to explore the variations between the sub-groups found in their experience of success in their work objectives. The research sample $(n=168)$ was analyzed using the Latent Profile Analysis (LPA) process. The study resulted in three subgroups of fatigue (exhaustion)-enthusiasm (vigor): 1) "Low exhaustion stability-high strength stability (Low stable exhaustion-high stable vigor)" ( $\mathrm{n}=$ 141), 2) "Fatigue and fluctuation strength (Fluctuating exhaustion and vigor)" ( $n=19)$ and 3) "Average stable exhaustion-decreased strength (Stable average exhaustion-decreasing force)" ( $\mathrm{N}=8)$. Three subgroups were also established for the dedication of cynicism (Low stable cynicism-strong stable dedication): 1) "Low stable cynicism-stable high dedication)" ((n = 124), 2) "Increasing cynicism-lower dedication" $(\mathrm{n}=27)$, and 3) "Reduced cynicism-increased dedication" $(n=17)$. The test results showed that exhaustion and excitement were very stable and mutually beneficial to the majority of participants. However, changes in the mean are also detected-especially in force-but such cases are uncommon. Another interesting finding was that the degree and change of cynicism and dedication showed opposite patterns in each subgroup: for the majority of participants (74 per cent), then the level of cynicism and dedication was fairly constant and inversely proportional, while another third simultaneously changed in the opposite direction. The most promising developments in personal work objectives were found in the groups identified by the identification spectrum, that is, in the groups "Low stable cynicism-high stable dedication" and "Reducing cynicism-increasing cynicism. dedication" (Decreasing cynicism-increasing dedication). Moreover, job engagement research indicates that planning the overall organizational output to compete and achieve the potential objectives in a competitive market climate is a management obligation. The key is to increase the dedication of employees to the company since we know that employees are the most valuable resources that can support the survival of the organization. [32] This study aims to increase the participation of employees at PT Maju Sentosa. This research was carried out by evaluating the current status of employees with different levels of participation at PT Maju Sentosa, examining the factors that affect employee engagement at PT Maju Sentosa, and also presenting findings and incremental recommendations to enhance future employee engagement that will contribute to better engagement. Production by PT Maju Sentosa. From the results of the study, it is understood that the current level of employee participation at PT Maju Sentosa is very strong and its engagement can be acknowledged but needs to be strengthened again, with an average score of 3.36 out of 5 scales and three important factors influencing employee participation at PT. Maju Sentosa is concerned with welfare, career, social support and job motivation. Employee involvement is a phenomenon that has seen positive outcomes over the last 10 years. Organizations today use employee engagement as a catalyst for strategic business partners. Employee engagement has become increasingly relevant, as several factors have been found that influence employee performance and well-being in their workplaces. [33] As a company that is active in the industry and strives to survive and win the tough competition, both physically and mentally. Employees will still be one of the main things that need to be centred on HR managers. Employee participation is also now seen as a source of strong competitive advantage in a time of global industrial rivalry. The study discussed the idea of employee engagement and also highlighted the main drivers of employee engagement by explicitly evaluating three primary factors, namely communication, work-life balance and leadership. This study will also analyze how these antecedents affect the level of performance and well-being of employees in the workplace. Various references available on employee engagement suggest that there is a lack of literature on these three factors and their impact on employee engagement. As a result, the study focused specifically on these three problems and produced substantial results. Based on an analysis of some of the previous literature, the proposed hypothesis is as follows.

H1: There is a significant effect of EE on OP.

$\mathrm{H} 2$ : There is a significant effect of LD on EE.

H3: There is a significant effect of MASIM on OP.

H4: MASIM strengthens the influence of EE on OP.

\section{RESEARCH METHODS}

This research uses a quantitative approach to survey methods and distributes questionnaires through online media (social media). The number of respondents was 280, based on the criteria: private tertiary education lecturer status, at least 1 year of teaching, willing to fill out a questionnaire without coercion and active status as a private university lecturer. Quantitative analysis using the CFA (Confirmatory Factor Analysis) method, SEM (Structural Equation Model) with AMOS, is the data analysis technique used in this study.

\section{DATA ANALYSIS AND DISCUSSION}

Results from the demographic study of respondents showed that $72.1 \%$ were male and the remaining $27.9 \%$ were female. Respondents were dominated by age groups over 35 years of age $(48.9 \%)$ and $96.8 \%$ were 
married. Besides, 92.5 per cent are those who have served for 6-10 years and all of them have at least a Master's degree.

The next stage of the study is to assess the validity and reliability of the data before the structural assessment of the research model is carried out by performing the confirmatory factor study (CFA) test as shown in Figure 1 below.

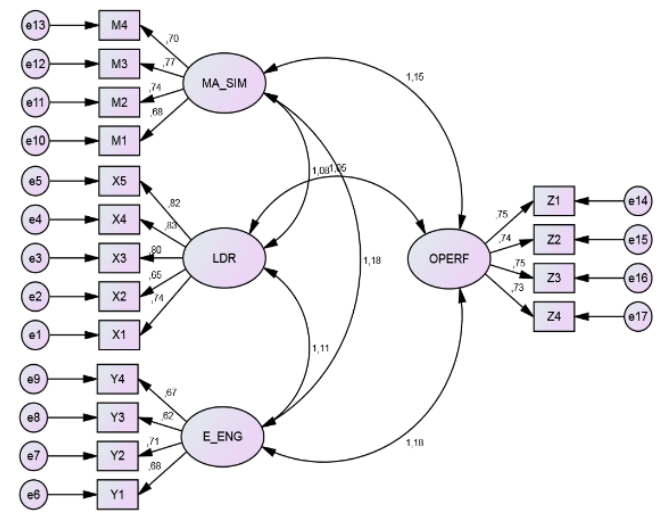

Figure 1. Measurement Model

Measurement models are used to validate the concept of construction based on the research model, the validity of the data can be calculated by the loading factor value and the tolerable value is greater than 0.5 . [48] The outcome of the analysis indicates that the loading factor value was above 0.5 . As a consequence of the configuration of the R2 (square-multiple correlation) in terms of building reliability (CR), the CR > 0.6 or 0.7 , so all the predictors of the proposed model are good and the results of the analysis indicate a benefit. The reliability of the design was above 0.6. [34] After validation and reliability are checked, the next step is to assess the normality of data, outliers and multilinearity of data. The results of the data normality test, based on the Critical Value Criterion for Skewness and Kurtosis, for confidence level $(\mathrm{P})=0.5$ are \pm 1.96 and the results indicate that there is no value beyond \pm 1.96 . [34] After all, metrics are accurate and reliable, the feasibility test of the research model is further evaluated using the goodness of the fit criteria with several index criteria and the cut-off of the values to make the research model fit or fine. The results of the test of the model with the appropriate parameters can be found in the table below.

Table 1. Goodness of fit index

\begin{tabular}{|c|c|c|c|}
\hline Goodness of Fit Index & Cut off Value & Model Test Result & Information \\
\hline Degree of Freedom & Positive $(+)$ & 111 & Positive \\
\hline Chi-Square & Expected: small & 252,445 & Marginal \\
\hline Significant Probability & $\geq 0,05$ & 0,000 & Acceptable \\
\hline CMIN/DF & $\leq 2,00$ & 2,274 & Marginal \\
\hline GFI & $\geq 0,90$ & 0,914 & Acceptable \\
\hline RMSEA & $0,05-0,08$ & 0,068 & Acceptable \\
\hline AGFI & $\geq 0,90$ & 0,881 & Marginal \\
\hline TLI & $\geq 0,90$ & 0,956 & Acceptable \\
\hline CFI & $\geq 0,90$ & 0,964 & Acceptable \\
\hline NFI & $\geq 0,90$ & 0,939 & Acceptable \\
\hline PNFI & $0,60-0,90$ & 0,766 & Acceptable \\
\hline
\end{tabular}

Source: Primary data processed by AMOS, (2020)
Based on the findings of the model feasibility test study, the structural test will be conducted at the next level and the amount of impact between the independent and the dependent variables will be analysed. The results of the SEM study using AMOS are shown below.

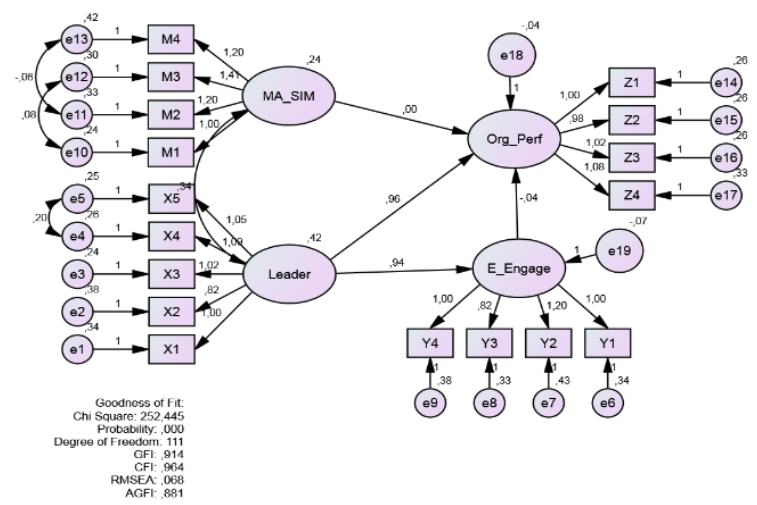

Figure 2. SEM Analysis

The results of the test show the magnitude of the effect between the variables in the figure. EE specifically impacts higher education performance negatively and insignificantly, so $\mathrm{H} 1$, which says "There is a major impact of EE on OP," can not be acknowledged. Furthermore, LD may have a significant effect on EE, so that $\mathrm{H} 2$, which says 'There is a significant effect of LD on EE,' may be acknowledged. Then directly MASIM also affects OP positively and insignificantly, therefore $\mathrm{H} 3$ which states "There is a significant effect of MASIM on OP" can not be believed. The results of the test can be seen in the table below.

Table 2. Result of SEM analysis

\begin{tabular}{|rrc|rr|}
\hline & & & Estimate & $P$ \\
\hline E_Engage & $<---$ & Leader &, 940 & $* \star \star$ \\
Org_Perf & $<---$ & MA_SIM &, 003 &, 965 \\
Org_Perf & $<---$ & E_Engage &,- 039 &, 482 \\
Org_Perf & $<---$ & Leader &, 964 & $* \star \star$ \\
\hline
\end{tabular}

Notice: $* * * \mathrm{P}$ value under 0,01

Source: Primary data (2020)

After testing the direct effect between variables, the next step is to examine the role of policy mediator variables that can strengthen or weaken MASIM 's influence on higher education performance. The results of the moderation test are shown below. 


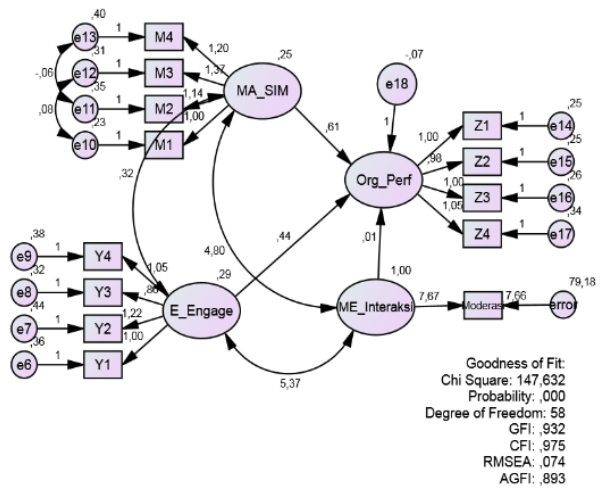

Figure 3. Result of Moderating Test

Test results of the influence of the moderating variable on the relationship between the variable engagement of lecturers and the performance of higher education.

Table 3. Result of Moderating Test

\begin{tabular}{|ccc|cc|}
\hline & & & Estimate & $P$ \\
\hline Org_Perf & $<---$ & MA_SIM &, 611 & $* * *$ \\
Org_Perf & $<---$ & E_Engage &, 437 & $* * *$ \\
Org_Perf & $<---$ & ME_Interaksi &, 008 & $* * *$ \\
\hline
\end{tabular}

Notice: *** $\mathrm{P}$ value under 0,01

Source: Primary data (2020)

Based on Table 3, MASIM would have a clear and substantial effect on higher education results by 0.611 . The presence of lecturers may also have a direct and important effect on higher education output by 0.437 and the ME Interacti variable, which is the product of the multiplication between EE and MASIM, shows a product of 0.008 and is important. This shows that the attachment of lecturers can have an influence on higher education performance and that the effect would be greater if enabled by the MASIM component, namely support for the use of meeting applications such as zoom or others.

Of course, the results of these various tests have implications for related parties in Aceh Private Higher Education and also confirm the results of previous research. This study confirms the findings of previous research, which shows a major impact of interaction on efficiency. [18][19][20][21][22][32] Besides, this study also supports previous findings that show the role of technology usage, such as meeting requests to enhance organizational efficiency[23][24] and confirms the results of other studies that examine the impact of leadership on performance. [10][11][12][13] Accordingly, based on the findings of this report, the progress of higher education performance will increase when considering several issues, namely:

1. Considering the factor of participation of lecturers, indirectly increasing the function of meeting applications such as zoom and others in lectures. Since research findings indicate that interaction would increase and increase if assisted by the use of meeting applications.

2. Considering the role of leadership, either directly or indirectly, both of which have a major effect on the performance of higher education and the participation of lecturers. This can be shown by leadership by always being secure in front of the lecturers and also by being prepared to defend and protect the interests of the lecturers at all times.

3. Since online activities or the use of online media are of high intensity rather than face-toface, it is best if the consistency of the network or link can be enhanced to facilitate the smooth operation of teaching and teaching activities.

\section{RESEARCH LIMITATION AND CONCLUSION}

This study, in addition to verifying previous research, has a drawback, namely that this research can not inherently be generalized to entities or institutions other than those with characteristics such as higher education institutions, in particular the profit sector, and thus it is suggested that it be re-tested by combining the types or characteristics of organizations or institutions. Which is different from this kind of analysis. Besides, this study has limitations on the diversity of respondents, consisting only of lecturers and a small number, so more study is recommended to be able to vary research respondents with more diverse occupations.

Based on the findings of the path review of the three variables LD, EE and MASIM for higher education efficiency, LD and EE have a major influence on the improvement of higher education efficiency. Besides, the MASIM variable may also enhance the impact of the EE on higher education results. The output of Aceh's private universities would therefore increase, taking into account these three variables, in particular the function of the moderating variable. Also, a variety of other items that can be used as an alternative strategy to boost the performance of Aceh's private universities are by increasing network communication capability in every Aceh private university, paying attention to and fighting for the rights of lecturers who have made an optimal contribution to the continuation of the Covid-19 pandemic.

\section{ACKNOWLEDGMENTS}

The author is a $\mathrm{PhD}$ student at the Faculty of Economics and Business at Syiah Kuala Banda Aceh University, also a lecturer at a private university in Banda Aceh, and the co-author is the author's promoter and co-promoter of the $\mathrm{PhD}$ program at the Faculty of Management Sciences. Economics and Business of Banda Aceh University of Syiah Kuala. Do not even forget that the 
author would also like to thank the promoters and copromoters who were willing to guide the author in completing this study.

\section{REFERENCES}

[1] Khan, William A. (1990). Psychological Conditions Of Personal Engagement And Disangagement At Work. The Academy of Management Journal, 33(4). pp692-724.

[2] Cropanzano, R., \& Mitchell, M.S. (2005). Social exchange theory: An interdisciplinary review. Journal of Management, 31, 874-900. doi: 10. 117710149206305279602.

[3] Maslow, A. H. (1943). A theory of human motivation. Psychological Review, 50(4), 370396. https://doi.org/10.1037/h0054346.

[4] Herzberg F., Mausner B., Synderman B. (1959). The motivation to work. NY: Wiley.

[5] Cummings, L. L., \& Elsami, A. M. (1968). Empirical research on the bases and correlates of managerial motivation: A review of the literature. Psychological Bulletin. 70(2), 127-144,

[6] Alderfer, Clayton P. (1969). An Empirical Test of a New Theory of Human Needs. Organizational Behavior And Human Performance. Vol 4, 142-175.

[7] Samad, Sarminah. (2012). The Influence Of Innovation And Transformational Leadership On Organizational Performance. Social and Behavioral Science, Vol 57.p486-493.

[8] Zehir, Cemal, Yasin Sehitoglu dan Ebru Erdogan. (2012). The Effect of Leadership and Supervisory Commitment to Organizational Performance. International Strategic Management Conference. Journal Social and Behavioral Science.Vol 58.p207216 ,

[9] Leroy, Hannes, Jesse Seger, Dirk van Dierendoncka dan Deanne den Hartog, (2018), Managing people in organizations: Integrating the study of HRM and leadership, Human resources management review. p19

[10] Soha, Hazalina Mat, Abdullah Osman, Shahrul Nizam Salahuddin, Safizal Abdullah, Nor Faizzah Ramlee, (2016). The Relationship of Work Influence, Sense of Community and Individual Spirituality towards Organizational Performance. Economic And Finance. Vol 35. p591-596.

[11] Silva, Graca Miranda, Chris Styles, Luis Filipie Lages, (2017). Breakthrough innovation in international business: The impact of tech-innovation and marketinnovation on performance. International Business Review. Vol 26, Issue 2, p391-404.

[12] Bakker, Arnold B dan Evangelia Demerouti, (2008).Toward A Model Of Work Engagement. Journal Career Development International.Vol 13. No 3. p209-22,

[13] Iddagoda, Anuradha dan Henarath H.D.N. Opatha.(2017). Identified research Gap In employee Engagement. International Business Research. Volume 10. No. 2. p63-73.

[14] Pauget, Bertrand dan Ahmed Dammak, (2018). The implementation of the Internet of Things: What impact on organizations?. Technological Forecasting \& Social Change.Vol 3. No 12. p1-7.

[15] Tajudeen, Farzana Parveen, Noor Ismawati Jaafar dan Sulaiman Ainin. (2017). Understanding the Impact of
Social Media Usage among Organizations. Journal Information and management.p1-38.

[16] Dajani, Maha Ahmed Zaki, (2015). The Impact of Employee Engagement on Job Performance and Organisational Commitment in the Egyptian Banking Sector. Journal of Business and Management Sciences.Vol. 3.No. 5.p138-147.

[17] MacCormick, Judith S, Kristine Dery, Darl G Kolb, (2012). Engaged or just connected? Smartphones and employee engagement. Organizational Dinamics. Vol 41.p194-201.

[18] Bersin, J. (2015). Becoming irresistible: A new model of employee engagement. Deloitte Review, (16), 145163. Retrieved from www.deloittereview.com,

[19] Perkins, D. D., \& Zimmerman, M. A. (1995). Empowerment theory, research, and application. American Journal of Community Psychology, 23(5), 569-579. https://doi.org/10.1007/BF02506982.

[20] Duggirala, M., Mehta, S., Kambhatla, N., \& Arya, P. (2012). Employee engagement: Conceptual model and computation framework. Annual SRII Global Conference, SRII, (July), 850-858. https://doi.org/10.1109/SRII.2012.111.

[21] Attridge, M. (2009). Employee Work Engagement: Best Practices for Employers. Research Works, 1(2), $1-12$.

[22] Rana, S., Ardichvili, A., \& Tkachenko, O. (2014). A theoretical model of the antecedents and outcomes of employee engagement: Dubin's method. Journal of Workplace Learning, 26(3), 249-266. https://doi.org/10.1108/JWL-09-2013-0063.

[23] Sartal, Antonio, Josep Llach, Xosé H. Vázquez, Rodolfo de Castro, (2017). How Much Does Lean Manufacturing Need Environmental And Information Technologies?. Elsevier Journal of Manufacturing System, Vol 45, p260-272.

[24] Chen, Yi-Cheng dan Jen-Her Wu, (2011). IT management capability and its impact on the performance of a CIO. Elsevier Journal of Information \& Technology, Vol. 48, p145-156.

[25] Sonnentag, Sabine, (2017), Atask-level perspective on work engagement:A new approach that helps to differentiate the concepts of engagement and burnout, Journal of Burnout Research, Vol 5, p12-20.

[26] Schaufeli, W. \& Bakker, A. (2004). Job Demands, Job Resources, And Their Relationship With Burnout And Engagement: A Multi-Sample Study. Journal of Organization Behavior. Vol.25. pp293-315.

[27] Hackman, JR and Oldham, GR. (1976) Motivation through the design of Work: Test of a Theory. Organizational Behavior and Human Performance. Vol 16, 250-279..

[28] Byrne, Z. S., Peters, J. M., \& Weston, J. W. (2016). The struggle with employee engagement: Measures and construct clarification using five samples. Journal of Applied Psychology, 101(9), 12011227. https://doi.org/10.1037/ap10000124

[29] Cole, Michael S., Frank Walter, Arthur G. Bedeian and Ernest H. O'Boyle. (2012). Job Burnout and Employee Engagement: A Meta-Analytic Examination of Construct Proliferation. Journal of Management. 38(5). p1550-1581.

[30] Huang, Yueng-Hsiang, Jin Lee, Anna C. McFadden, Lauren A. Murphy,Michelle M. Robertson, Janelle H. Cheung, Dov Zohar, (2016). Beyond safety outcomes: An Investigation Of The Impact Of Safety Climate On Job Satisfaction, 
Employee Engagement And Turnover Using Social Exchange Theory As The Theoretical Framework, Journal Of Applied Ergonomics, Vol 55, p248-257.

[31] Mäkikangas, Anne, Katriina Hyvönen, Taru Feldt, (2017). The Energy And Identification Continue Of Burnout AndWorkEngagement: Developmental Profiles Over EightYears. Journal of Burnout Research, Vol 5, p44-54.

[32] Stephanie dan Aurik Gustomo, (2015). Proposal to Improve Employee Engagement in PT Maju Sentosa by AON Hewitt Model and Mercer Model. Social and Behavioral Sciences, Vol 169, p3630-370.

[33] Bedarkar, Madhura dan Deepika Pandita, (2014). A study on the drivers of employee engagement impacting employee performance. Social and Behavioral Sciences, Vol 133, p106-115.

[34] Hair, J. R., Joseph, F., Rolp, E., Anderson, Ropnald, L., Tatham and William, C. Black. (2010). Multivariate Data Analysis with Reading. Fourth Ed., Prentice Hall International, Inc.. 